\title{
An Investigation on the Economic Feasibility of Macroalgae as a Potential Feedstock for Biorefineries
}

\author{
N. V. S. N. Murthy Konda • Seema Singh • \\ Blake A. Simmons $•$ Daniel Klein-Marcuschamer
}

Published online: 6 March 2015

(C) The Author(s) 2015. This article is published with open access at Springerlink.com

\begin{abstract}
Macroalgal biomass has been considered as a prospective feedstock for biofuel production as, among other benefits, it is an abundant source of renewable sugars and its growth does not require arable land, fresh water, or intense care. Successful commercial deployment of macroalgae-based biorefineries, however, depends on their economic viability at industrial scales. A key objective of this study was to carry out a detailed technoeoconomic analysis (TEA) of a macroalgae biorefinery to understand the economic potential and cost drivers of macroalgae as a feedstock for the production of biofuels and biochemicals. Ethanol was used as a representative macroalgae-derived product, given the wealth of public information available to model this option, and the analysis was extended to biomass-derived sugars in order to explore the production of other fermentation-derived chemicals. Sen-
\end{abstract}

N. V. S. N. M. Konda $\cdot$ S. Singh $\cdot$ B. A. Simmons $\cdot$

D. Klein-Marcuschamer $(\square)$

Joint BioEnergy Institute, 5885 Hollis St., Emeryville, CA 94608,

USA

e-mail: dklein@lbl.gov

N. V. S. N. M. Konda

e-mail: MurthyKonda@lbl.gov

S. Singh

e-mail: ssingh@lbl.gov

B. A. Simmons

e-mail: basimmons@lbl.gov

N. V. S. N. M. Konda • D. Klein-Marcuschamer

Physical Biosciences Division, Lawrence Berkeley National

Laboratory, Berkeley, CA 94720, USA

S. Singh $\cdot$ B. A. Simmons

Biological and Materials Science Center, Sandia National

Laboratories, Livermore, CA 94551, USA

D. Klein-Marcuschamer

Dow Center for Sustainable Engineering Innovation, University of

Queensland, St. Lucia, QLD, Australia sitivity analysis was performed on various cost drivers, such as macroalgae price, yield, solids loading, and enzyme loading during hydrolysis. With a feedstock price of $\$ 100 / \mathrm{MT}$, depending on the maturity of the other key process parameters (i.e., yield, solids loading, and enzyme loading), the minimum ethanol selling price (MESP) was observed to be in the range of \$3.6-8.5/gal and reduced to \$2.9-7.5/gal with macroalgae priced at $\$ 50 / \mathrm{MT}$. For production of chemicals, sugar prices were in the range of $\phi 21-47 / \mathrm{lb}$ or $\phi 16-40 / \mathrm{lb}$ with macroalgae priced at $\$ 100 / \mathrm{MT}$ and $\$ 50 / \mathrm{MT}$, respectively. Given the challenging economics of the macroalgae biorefinery, coproduction of alginate was used to show the importance of multiple revenue sources, though issues regarding market saturation continue to arise when dealing with products of disparate market sizes.

Keywords Macroalgae biorefinery $\cdot$ Technoeconomic analysis (TEA) · Advanced biofuels · Alginate extraction · Renewable sugars

$\begin{array}{ll}\text { Abbreviations } \\ \text { CapEx } & \text { Capital expenditure } \\ \text { IRR } & \text { Internal rate of return } \\ \text { MESP } & \text { Minimum ethanol selling price } \\ \text { MSP } & \text { Minimum selling price } \\ \text { Mgal } & \text { Million gallons } \\ \text { OpEx } & \text { Operating expenditure }\end{array}$

Introduction

Nonedible sources of biomass, both terrestrial and marine, are generally considered as advantaged feedstocks for the production of next-generation biofuels and chemicals as they do not compete with the primary food supply chains. Unlike terrestrial biomass (e.g., lignocellulosic biomass), marine-based 
macroalgae (also known as seaweeds) do not require arable land or fresh water for cultivation. Due to structural differences, the photosynthetic efficiency of seaweeds is, on average, about three to four times that of the terrestrial biomass ( 7 vs $2 \%$, respectively $[1,2])$. Macroalgae grows more rapidly resulting in higher primary production rates in the order of 30 83 dry MT/ha/year as opposed to 3-30 dry MT/ha/year in the case of crops such as maize, sugarcane, corn stover, or poplar [2-5]. Given the diversity and abundance of macroalgae [2] and the richness of their carbohydrate content, these aquatic organisms are a relatively abundant source of renewable carbon that could be productively tapped for the production of renewable fuels and chemicals. The numerous macroalgae species found worldwide are broadly classified into three groups: brown, red, and green. Brown seaweed is the single largest macroalgae resource and is considered to be one of the most likely contenders for the production of biofuels and chemicals [2]. The brown macroalgae are particularly attractive for fermentation-derived products due to their high content of carbohydrates and near or full absence of lignin.

Despite these advantages, the commercial viability of macroalgae-based biorefineries depends on the economic performance of the processes that are involved in the conversion of macroalgae to biofuels and/or chemicals at industrial scales. In this regard, technoeconomic analysis (TEA) can help understand the economic potential and identify cost drivers associated with these processes. While many studies concerning the economics of lignocellulosic biorefineries have been published (e.g., [6-9]), pertinent studies on macroalgae biorefineries are scarce. A preliminary analysis carried out by Pacific Northwest National Laboratory [2] identified the maximum allowable seaweed feedstock price to be \$28/MT (dry), in order to produce ethanol at $\$ 2.2 /$ gal or less, which was at the lower end of the estimated seaweed production cost range (\$21-112/MT depending on the type of species and cultivation method employed). The study highlighted the need for advances throughout the supply chain (especially macroalgae production cost reduction), but specific cost drivers were not identified. A recent TEA study [10] has focused on biogas production from macroalgae in a small community-scale facility.

The main objective of our study was to carry out a detailed TEA of the production of fermentation-derived products from macroalgae at an industrial-scale facility with $2000 \mathrm{MT}$ /day dry biomass processing capacity. We focused on determining the economic potential and cost drivers of a macroalgae-based biorefinery and investigated specific opportunities to improve the overall biorefinery economics. We used ethanol as a representative biofuel and extended the analysis to macroalgaederived sugars to include the potential production of biochemicals and other biofuels. Lastly, we explored the possibility of using alginate as a value-added coproduct to improve the economic performance of the biorefinery.

\section{Materials and Methods}

\section{Feedstock Composition}

Saccharina latissima (also known as Laminaria saccharina), a brown seaweed, is used as a model feedstock in this study. Primary carbohydrates in the brown macroalgae are as follows: laminarin (a polysaccharide of glucose), mannitol (a 6carbon sugar alcohol), and alginate (the salt form of alginic acid, which in turn is a linear polymer of mannuronic acid and guluronic acid). Given the seasonal variation in the composition of seaweed [11], averaged data of three macroalgae samples obtained from different harvests (Dec 2011, Jul 2011, and Aug 2011 [12]) was used in our analysis (after adjusting for moisture, see next paragraph). The representative composition of the brown algae and lignocellulose are given in Fig. 1. On a dry basis, about two thirds of the macroalgae feed is composed of carbohydrates (with half of it being alginate) and the rest is ash/salt. Compared to lignocellulosic biomass, the main
Brown macroalge composition (S. latissima, dry basis)

Avg. of three harvests: Dec-2010, July \& Aug-2011

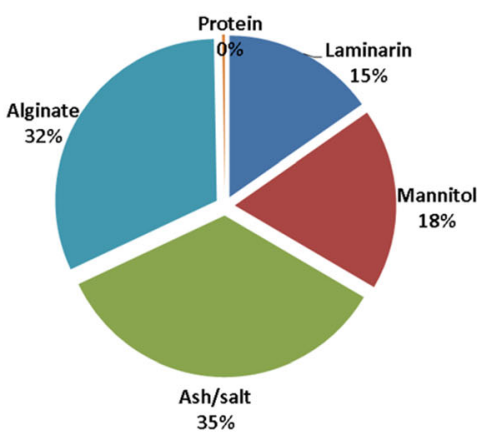

Lignocellulosic biomass composition (corn stover, dry basis, NREL 2011)

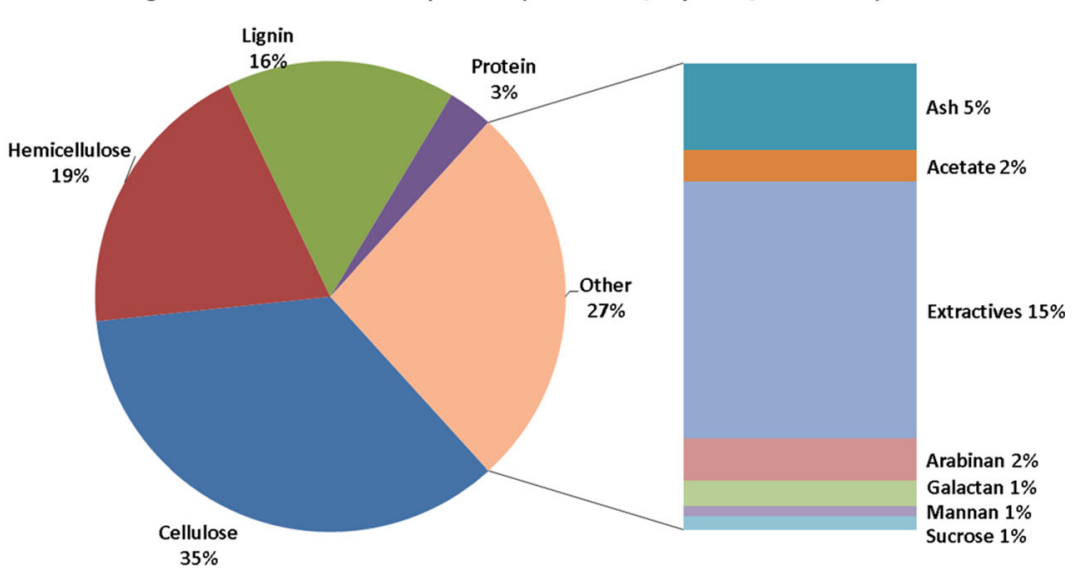

Fig. 1 Representative composition (dry basis) of brown macroalgae (S. latissima) and lignocellulosic biomass (corn stover) 
differences include the absence of lignin (as opposed to $\sim 16 \%$ lignin in the case of corn stover) and much higher quantities of ash/salt (i.e., $35 \%$ in macroalgae vs $5 \%$ in corn stover). While the absence of lignin favors the use of macroalgae, the presence of a significant amount of salts may pose a challenge for this feedstock. Downstream processes, such as enzymatic hydrolysis and fermentation, must operate at high salinity because removing salts through washing results in loss of sugars (e.g., [12]), increases fresh water usage and incurs additional costs for wastewater treatment [13]. Furthermore, Scullin et al. [12] observed that the washing results in a higher alginate to glucan ratio (compared to unwashed samples), which in turn increased viscosity and reduced sugar yield [12]. For these reasons, the macroalgae feedstock was assumed to arrive at the plant gate unwashed.

Moisture Content in the Delivered Feedstock at the Plant Gate

Water content is another issue that must be addressed, as freshly harvested brown seaweed typically contains $80-90 \%$ water [2]. Dewatering may not be necessary as the downstream operations (such as fermentation, anaerobic digestion, or even hydrothermal liquefaction) have high tolerance or requirement for water. However, dewatering may be important as a method to increase shelf-life and reduce the associated transportation costs [14]. Harvested brown seaweeds are generally stored for several hours (or even days), prior to dispatch/delivery, at ambient temperature [14]. In the case of brown algae, ambient storage is not considered as a problem as they are resistant to microbial degradation due to the polyphenols present. During this period, natural dewatering takes place and the moisture content decreases. Dewatering to about $20-30 \%$ water content has been noted to have a stabilizing effect and is beneficial for transportation. Further drying is generally energy and labor intensive [13] and is usually not practiced. For the purposes of this study, it was assumed that the delivered feedstock at the plant gate contains $\sim 25 \%$ moisture (e.g., after natural dewatering during ambient storage at the harvesting site and during transportation to the biorefinery).

\section{Macroalgae-to-Ethanol Biorefinery Configuration}

In order to perform a biorefinery-wide TEA, a process model was developed in SuperPro Designer [15]. The model was largely based on a recent study by the National Renewable Energy Laboratory (NREL) on the production of ethanol from corn stover [8], modified for the processing of macroalgae and its products. A simplified block flow diagram of the biorefinery is shown in Fig. 2. The biorefinery was modeled to represent an industrial-scale facility and processes 2000 MT/day of dry macroalgae. As shown in Fig. 2, ethanol production from macroalgae involves four major consecutive steps: feedstock handling, hydrolysis, fermentation, and product recovery. Due to the absence of lignin (Fig. 1), it was assumed that pretreatment was not needed as suggested by a previous study [3]. Polysaccharide components (i.e., laminarin and alginate) were converted into their monomeric form in the enzymatic hydrolysis section; the resulting hydrolyzate was sent to the fermentation section. All the fermentable sugars (i.e., the reducing sugars from laminarin and alginate, together with mannitol) were cofermented to ethanol. The resulting ethanol broth then entered the product recovery section. Product recovery was composed of a distillation column (i.e., preconcentrator), a rectifying column, and a molecular
Fig. 2 Simplified representation of the macroalgae-to-ethanol biorefinery (the red crossing represents the absence of pretreatment, which would otherwise be present in a regular lignocellulosic biorefinery)

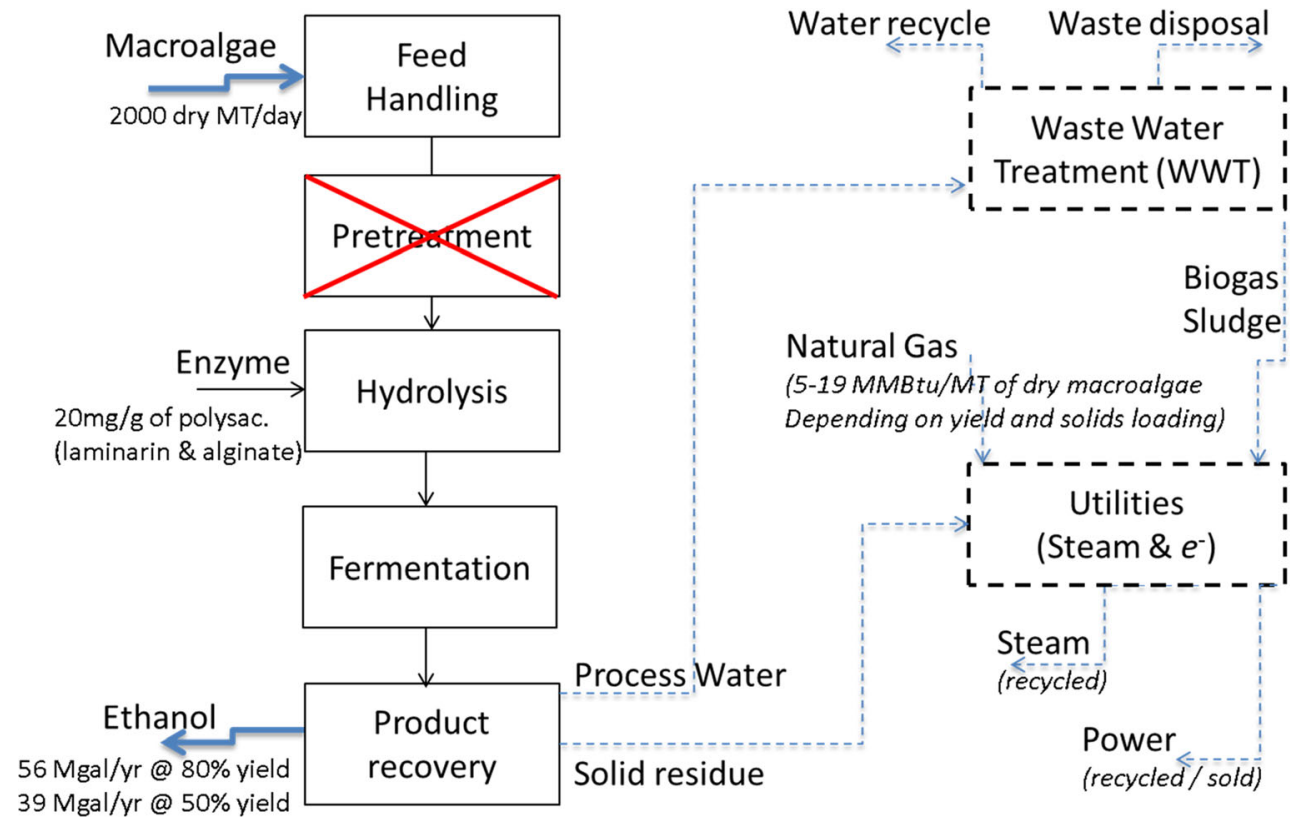


sieve system, which together produced ethanol of $>99.6 \%$ purity. Stillage from the bottom of the preconcentrator was processed in a filter press to separate the thin stillage (rich in water) from the solid cake.

In addition to the sections discussed above, there are two auxiliary sections: wastewater treatment (WWT) and cogeneration (or utility). The auxiliary sections were closely integrated with the other sections in the plant. The thin stillage from the product recovery section, together with the used water from other parts of the biorefinery, was processed in the WWT section, where most of the solids were digested in an anaerobic digester based on previous findings $[13,16]$. Biogas and sludge from the WWT section, together with the solid cake from the product recovery section, were utilized as fuel in the steam boiler in the cogeneration section to meet the steam needs of the biorefinery. The cogeneration section was designed such that the plant was self-sufficient with respect to steam. In scenarios where the steam produced by burning the process solid residues and biogas was not sufficient, natural gas was purchased from external sources to meet the overall steam demand of the biorefinery. Excess steam was used in a multistage turbo generator to produce electricity; this electricity was used for the process needs and any surplus electricity was sold to the grid.

\section{Base Case Macroalgae-to-Ethanol Biorefinery Model Specifications}

Given the uncertainty in several process and economic parameters, a base case was first established as discussed below. This base case model was used to identify the key cost drivers, and a detailed sensitivity analysis was then carried out to understand the impact of these cost drivers on the overall biorefinery economics. The baseline values of these key parameters were estimated based on the literature:

- Feedstock price: As discussed earlier, the original samples used to estimate the feedstock composition in this study, though dried and stored, contain small amounts of moisture ( $6.6 \mathrm{wt} \%$ on average). Hence, unless otherwise stated, the price of feedstock in this study is based on the macroalgae with $6.6 \mathrm{wt} \%$ moisture content. Furthermore, the feedstock price in this study represents the delivered price of macroalgae at the plant gate. Depending on the type of macroalgae and cultivation method, the production costs could vary in the range of $\$ 21-120 /$ MT of macroalgae. The delivered price would be higher due to the additional costs involved for harvesting, cleaning (e.g., removal of debris), processing (e.g., milling or shredding, drying, etc.), and other supply chain logistics (e.g., collection, transportation, storage, delivery, etc.). Currently, for macroalgae feedstock, most of these aspects are either not yet established or not commonly available. In the case of corn stover feedstock, for instance, these additional costs would add up to about 1.5 times as much as the production cost itself [8]. Given these considerations, the base case feedstock price was assumed to be \$100/MT.

- Yield: In this study, this term is used to represent the "percent of the theoretical overall yield," with the maximum theoretical yield from feedstock to product being normalized to $100 \%$. For example, at $100 \%$ yield, every kilogram of macroalgae (with $6.6 \mathrm{wt} \%$ moisture) produces $0.58 \mathrm{~kg}$ of sugars in the hydrolysis section and, subsequently, $0.31 \mathrm{~kg}$ of ethanol in the fermentation section. Typically, the achievable yield in practice depends on several factors related to hydrolysis (e.g., enzyme type and loading, operating conditions, etc.) and fermentation (e.g., microorganism employed, pathway modifications, etc.). While the maximum reported yield for brown algae is about $80 \%$ [17], the yield can be affected significantly depending on the aforementioned factors, in addition to the composition of the incoming feedstock. The effect of the seasonal variation in composition can be significant: one study showed that fermentation yield could be dropped to as low as $28 \%$ [11]. In this study, we assumed a $50 \%$ yield for the base case scenario. This value was realized with an average polysaccharide conversion of $67 \%$ in the hydrolysis reactor (i.e., laminarin and alginate to monomeric sugars) and with an average sugars-toethanol conversion of $67 \%$ in the fermentation reactor.

- Solids loading: This refers to the $\mathrm{wt} \%$ of solids in the hydrolysis reactor. Due to the viscous nature of alginate, which is present in significant quantity in brown algae (see Fig. 1), a high solids loading ( $>5 \%$ ) would result in a highly viscous solution [11], which could in turn have a detrimental impact on sugar yield and increase the pumping and agitation power requirements. At low solids loadings, viscosity and inhibitor concentration are low thus facilitating a higher sugar yield. In addition, high solids loadings result in high salinity (e.g., $75 \mathrm{~g} / \mathrm{L}$ at $20 \%$ solids loading), which is not favorable for commercial enzymes and microbes (e.g., [3]). In the base case scenario, a relatively low $5 \%$ solids loading was assumed. For comparison, lignocellulosic biomass biorefineries are typically designed to operate at $\sim 20 \%$ solids loading [8].

- Enzyme loading: Based on previous studies [12, 17, 18], for the base case scenario, an enzyme loading of $20 \mathrm{mg} / \mathrm{g}$ of hydrolysable polysaccharides (i.e., laminarin and alginate) was used. Based on a previous study, an enzyme price of $\$ 10.14 / \mathrm{kg}$ of protein was assumed [19].

Macroalgae-to-Sugars Process Configuration

The macroalgae biorefinery was modified (i.e., by removing the fermentation and ethanol recovery/purification sections) to 
evaluate the economic potential of macroalgae as a feedstock to produce fermentable sugars for production of fuels or chemicals. To be clear, the idea was not to produce sugar as an end-product that can be sold in the sugar market, but rather to determine the economic value of sugars in the hydrolyzate stream, relative to other alternatives (e.g., sugars from sugarcane, corn syrup, etc.) that could be used as substrates for fermentation-based products. Subsequently, there was no sugar recovery/purification section downstream of the hydrolysis section. In order to accommodate for the fact that not all sugars in the hydrolyzate are assimilated by the fermenting microbes to the same extent, the price of sugars was computed on the basis of effective fermentable sugars in the hydrolyzate. In other words, similar to the base case macroalgae-to-ethanol biorefinery discussed above, for the base case macroalgae-tosugars platform, only $67 \%$ of the total sugars present in the hydrolyzate were assumed to be "convertible" if there were a fermentation section downstream of hydrolysis, because the macroalgae sugars are not fungible to sucrose or glucose.

Coproduction of Alginate and Ethanol in the Macroalgae Biorefinery

Alginate was explored as a coproduct to understand the economic value of adding this revenue stream to the biorefinery operation. Unlike laminarin, which is a storage polysaccharide, alginate is a structural polysaccharide in brown algae. It was assumed that the alginate in the feedstock is present as calcium alginate $(\mathrm{Ca}(\mathrm{alg}))$, as this is more prevalent compared to other alkali salt forms [20]. The previously described biorefinery model (i.e., macroalgae-to-ethanol) was modified by adding an alginate extraction process prior to hydrolysis. Through this process, food-grade alginate is assumed to be extracted in sodium alginate form $(\mathrm{Na}(\mathrm{alg}))$, which is the more widely used/sold form compared to other alkali salt forms [21, 22].

A detailed alginate extraction process, involving multiple steps, was modeled (Fig. 3) based on pilot-scale experiments reported in the literature [20, 23-25]. Briefly, macroalgae was first soaked in a formalin solution for $12 \mathrm{~h}$ and then washed with acid $(\mathrm{HCl})$. The preprocessed biomass was then stirred in a hot alkali solution $\left(\mathrm{Na}_{2} \mathrm{CO}_{3}\right)$. Over a period of $2 \mathrm{~h}$, insoluble $\mathrm{Ca}(\mathrm{alg})$ transformed into soluble $\mathrm{Na}(\mathrm{alg})$ resulting in a thick slurry. To facilitate removal of the insoluble solids via filtration, the slurry was diluted with a large quantity of water. The solution was sent through a rotary vacuum filter and the residue was removed from the top and sent to the hydrolysis section where laminarin and residual alginate, together with mannitol, were assumed to be processed into ethanol (which was shown to be technically feasible [26]), using the macroalgae-to-ethanol biorefinery configuration discussed above. The filter extract solution (i.e., $\mathrm{Na}(\mathrm{alg})$ with $99.5 \mathrm{wt} \%$ water), was processed through a series of chemical treatments (using $\mathrm{CaCl}_{2}, \mathrm{NaOCl}, \mathrm{HCl}$, and $\mathrm{Na}_{2} \mathrm{CO}_{3}$ ) and water removal operations (i.e., metal screening and belt press) to obtain $\mathrm{Na}(\mathrm{alg})$ in a paste form. The $\mathrm{Na}(\mathrm{alg})$ paste was further dried in a rotary dryer to reduce the moisture content to about $10 \mathrm{wt} \%$. Using this extraction process, an overall yield (i.e.,
Fig. 3 Block flow diagram of the alginate extraction process

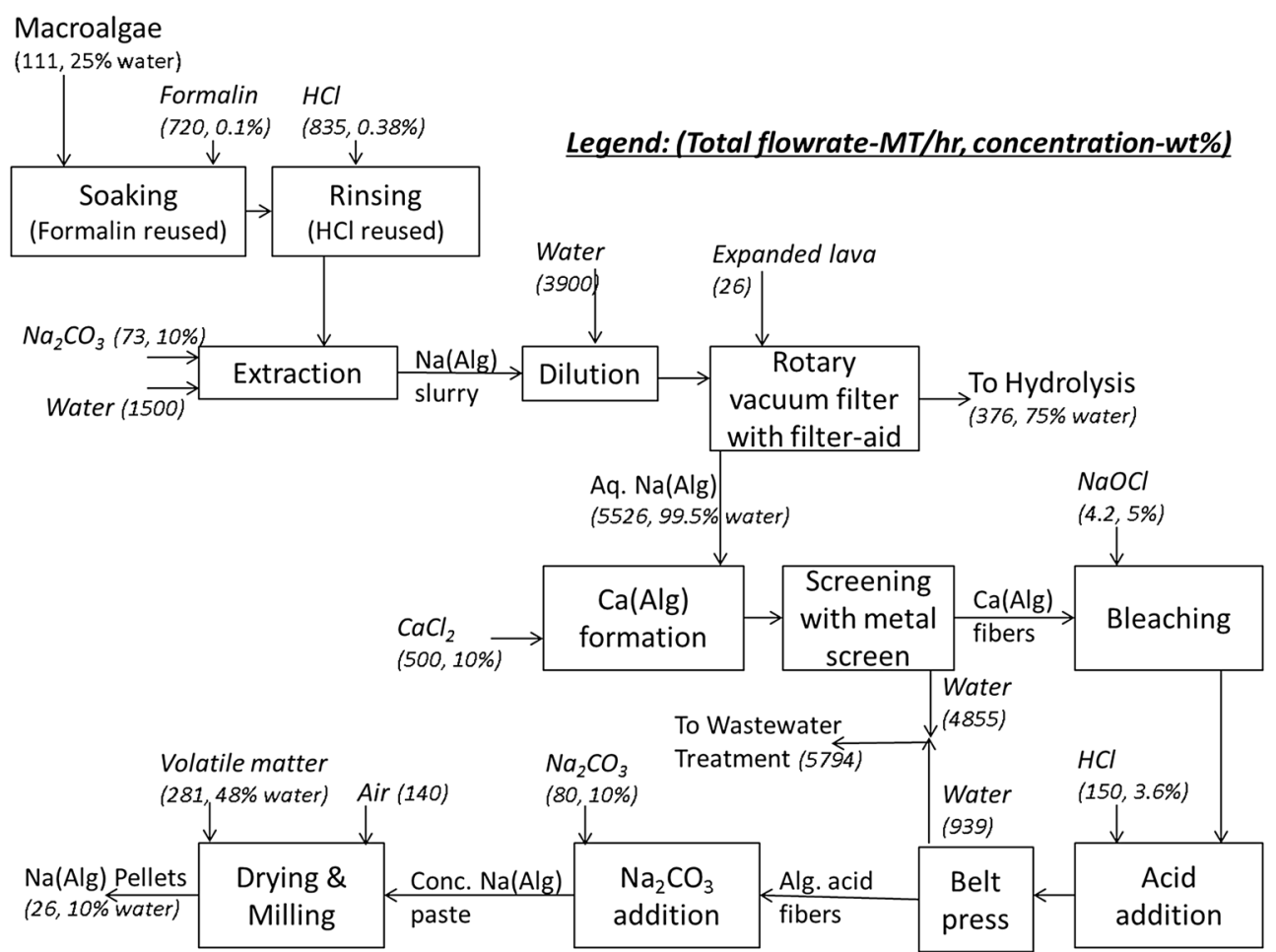


ration between the alginate extracted in the product and the alginate present in the feed, $w / w$ ) of $88 \%$ was assumed [25].

Cost Analysis For the TEA, the purchase, installation, and maintenance costs of major pieces of equipment, costs of labor, utilities, and raw materials (except feedstock) were based on previous technoeconomic studies [6-8, 27-29]. The reference year was updated to 2012 and, accordingly, the costs were adjusted using the Chemical Engineering Plant Cost Index (CEPCI) and inflation data. The financial assumptions and the economic analysis were taken from previous studies $[27,29]$. In line with these studies, the results were reported in terms of the minimum ethanol selling price (MESP; in case of sugars and alginate, minimum selling price (MSP), was reported) -i.e., the selling price obtained from a detailed cash flow analysis corresponding to an internal rate of return (IRR) of $10 \%$.

\section{Results and Discussion}

\section{Macroalgae-to-Ethanol Biorefinery—Base Case Analysis and Cost Drivers}

In order to assess the economic viability of macroalgae as a feedstock for fermentation-based products, we began by analyzing the production of ethanol. From the detailed TEA, the MESP for the base case was $\$ 8.5 / \mathrm{gal}$, emphasizing the need for further technological advances. A detailed breakdown of the total annual operating cost (AOC) is given in Fig. 4. From this, it can be seen that the key cost contributors include the feedstock, hydrolysis enzymes, natural gas, and facilitydependent (mostly capital) costs. The facility-dependent costs include depreciation, maintenance, and insurance - in other words, this component represents the costs related to capital expenditure (CapEx), directly or indirectly. Based on this analysis and our previous experience, we decided to further explore the effect of the solids loading, yield, feedstock price, and enzyme loading on the MESP through sensitivity analysis. Firstly, the solids loading affects the facility-dependent as well as the utility operating costs. Systems with low solids loadings (as in the base case) are dilute, thus requiring relatively larger equipment in almost all sections of the plant (i.e., hydrolysis, fermentation, product recovery, and WWT). Such systems also consume more utilities to move, mix, heat, and cool various process streams and for product recovery. Secondly, the yield affects almost all cost contributions, because at lower yields the production costs are incurred to obtain lower revenues. Thirdly, the feedstock price that can be secured to operate the biorefinery is subject to much speculation, and hence, this parameter was further studied. Lastly, enzymerelated costs are both significant and uncertain. Even though both enzyme price and usage can alter this cost contribution, the price was fixed in this study at $\$ 10.14 / \mathrm{kg}$ of protein [7] and enzyme loading was studied during sensitivity analysis.

\section{Sensitivity Analysis (Macroalgae-to-Ethanol Biorefinery)}

TEA of several scenarios was carried out to understand the impact of innovation on the MESP. These include the scenarios with technological advances affecting the individual cost drivers previously described (i.e., solids loading, yield, feedstock price, and enzyme loading) as well as an "aggregate scenario" to evaluate the collective impact of advances in all these fronts. The cost drivers were all studied at varying feedstock price because of the particular uncertainty and weight of this parameter. The MESP values obtained from these scenarios are given in Fig. 5. From this analysis, it can be seen that the MESP for the base case was in the range of $\$ 6.5-10.5 / \mathrm{gal}$ as the feed price changes from $\$ 0$ to $\$ 200 / \mathrm{MT}$. While the
Fig. 4 Breakdown of annual operating cost (AOC) for the base case macroalgae-to-ethanol biorefinery

\section{Annual Operating Cost (AOC) breakdown}

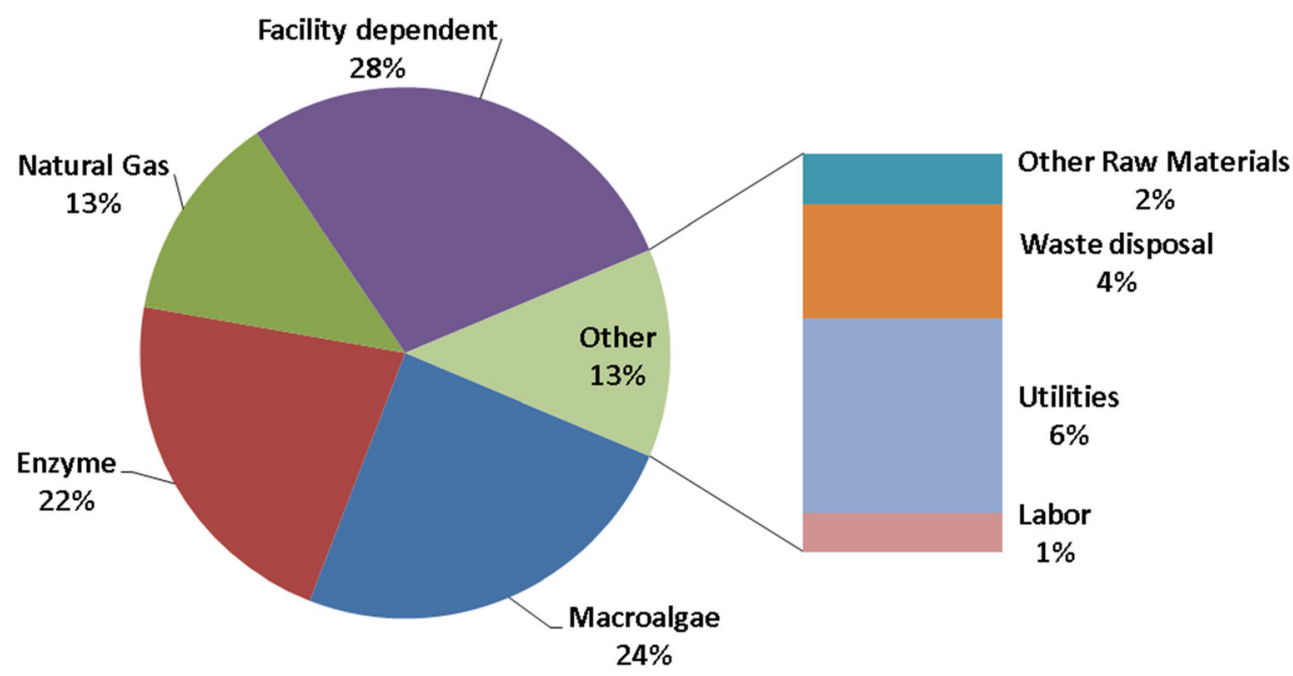


Fig. 5 Impact of macroalgae price, yield, solids loading, and enzyme loading on MESP of macroalgae-to-ethanol biorefinery

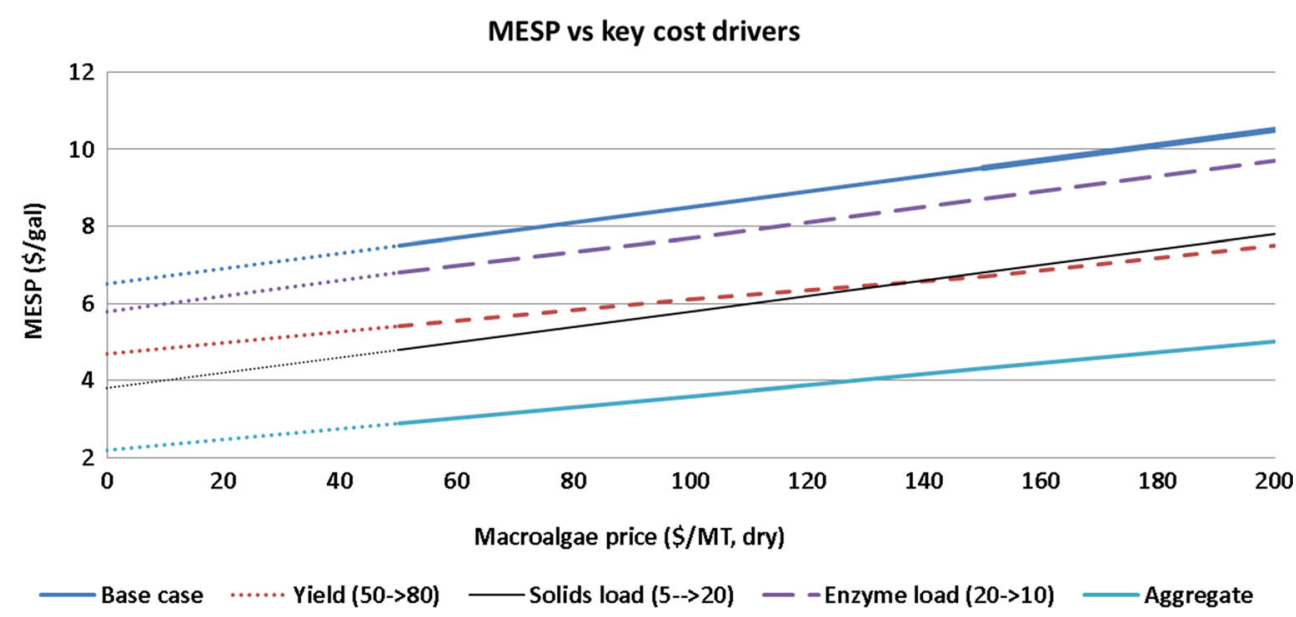

delivered feed price cannot be zero in practice, the intention of including this data point was to understand the challenge associated with factors other than the feed price. For example, a base case MESP of \$6.5/gal at \$0/MT macroalgae emphasizes the importance of developing technologies related to the process itself. If the feed price were to be fixed at $\$ 100 / \mathrm{MT}$ (as in the base case), the MESP would vary in the range of \$3.6-8.5/ gal depending on the other parameters (i.e., yield, solids loading, and enzyme loading). Other observations that can be drawn from this sensitivity analysis (5) are discussed below:

- Impact of feedstock price: Overall, every \$50/MT increase (or decrease) in the feed price, increases (or decreases) the MESP by \$0.6-1.0/gal depending on the yield range studied $(50-80 \%)$.

- Impact of yield improvement: Similar to the base case, the overall yield of $80 \%$ was achieved by assuming an average conversion of $87 \%$ in both the hydrolysis and fermentation reactors. The improvement in yield (from 50 to $80 \%$ ) reduced the MESP by $\$ 1.8-3.0 /$ gal depending on the feed price. The MESP, however, remained more than $\$ 4.5 /$ gal in this scenario. Another interesting observation was that the impact of the feed price is reduced at higher yield (i.e., the line is flatter than for other cost drivers). Furthermore, even at zero feedstock price, the yield has an impact on the MESP because at higher yields, nonfeedstock costs are "amortized" over a larger number of product units (in this case, ethanol gallons).

- Impact of solids loading improvement: The improvement in the solids loading (from 5 to $20 \%$ ) reduced the MESP by $\$ 2.7 /$ gal irrespective of the feedstock price. In other words, this parameter was found to be as significant as the yield for reducing the MESP. This is because the solids loading significantly affects both the CapEX and OpEX. In fact, around half of the MESP benefit came from the reduction in CapEX: compared to the base case, the improved solids loading reduced the AOC by $\$ 102$ million, of which $\$ 53$ million was due to the lower facility- dependent costs alone. Despite this advancement, the MESP remained above $\$ 4 /$ gal in our analysis, even at $20 \%$ solids loading.

- Impact of enzyme loading improvement: As the enzyme loading decreased (from 20 to $10 \mathrm{mg} / \mathrm{g}$ of hydrolysable polysaccharides), the MESP was reduced by $\$ 0.8 /$ gal.

- The aggregate scenario: If all the advances were to be simultaneously implemented, the MESP would be reduced by about $\$ 4.3-5.5 /$ gal compared to the base case, depending on the price of macroalgae. Overall, even with all these advances, the MESP was \$3.6/gal at \$100/MT macroalgae.

Even if all the advances of the aggregate scenario are implemented and have the effects described above, the feed price would have to be $\$ 26 / \mathrm{MT}$ or lower to ensure that the MESP is below $\$ 2.5 /$ gal (equivalent to the average market price of ethanol during 2012-2013 [30]). Based on a recent study [10], however, the cultivation cost itself could be \$54/MT (€40/ MT), suggesting that the delivered price is likely to be much higher than \$26/MT. The high cost of macroalgae could be partly due to the energy intensity of its production. For instance, a detailed life cycle energy analysis [31] suggested that macroalgae production (cultivation and harvest) was the most energy intensive step and consumes about $30 \%$ more energy than the total energy required in all the steps involved in the conversion of macroalgae to ethanol.

Furthermore, it was assumed that all the parameters can be independently manipulated, which is not necessarily true. For instance, as the solids loading increases, yield may drop (e.g., $[32,33])$ or higher enzyme loading may be necessary to retain yield. Due to the lack of such experimental studies in the literature, possible interactions among these parameters are ignored in this study. Other factors could not be considered in the present study due to lack of data. For example, compared to lignocellulosic biomass, the sulfur and nitrogen content in macroalgae is relatively high [2], which may increase the production cost through gas cleaning units in the boiler 
flue gas. Any acid added to the hydrolysis reactor (to regulate $\mathrm{pH}$ ) and any base added subsequently (for neutralization) would not only incur higher raw material costs, but also add to the already-high salt concentration, which may impact the fermentation (e.g., [3]). In practice, the MESP values are likely to be higher than the values in this study, emphasizing the economic challenge facing the biorefinery.

The above discussion highlights the importance of multiple and concerted technology advances if macroalgae-based ethanol were to be economically viable. Improving the yield, solids loading, etc. are challenging goals on their own merits, and even more so because they must be accomplished in the context of high salinity and viscosity (due to high salt and alginate content, respectively). In other words, while the absence of lignin makes macroalgae an attractive feedstock for biorefineries, the presence of significant amounts of salts and alginate poses additional challenges. The significant amount of salts present in macroalgae results in high salt concentrations especially at high solids loading; for instance, at $20 \%$ solids loading, the salt concentration in the hydrolysis section was $75 \mathrm{~g} / \mathrm{L}$, which is about two times that typically in seawater. It has been previously shown that high salt concentrations negatively impact cell growth, sugar conversion rates, and ethanol productivity [3, 34]. Furthermore, increased viscosity at high solids loading is likely to have a detrimental impact on sugar yield (e.g., [33]). Innovation on this front could involve development of the thermophilic enzyme cocktails, which could facilitate hydrolysis at sufficiently high temperature, thereby reducing viscosity (which otherwise is a significant challenge).

Prospects for Macroalgae-Based Fermentation-Derived Products

The analysis implied that the production of ethanol from macroalgae is unlikely to compete with the ethanol produced from other sources (i.e., the ethanol sold today in the marketplace). However, many other biochemicals can be produced by fermentation of the sugars present in the macroalgae, and these may present an opportunity for the use of the feedstock. In other words, an ethanol-producing biorefinery may not be a good representative candidate scenario in determining the potential of macroalgae as a biomass feedstock, either because the ethanol production cost is inherently high or because the revenue provided by ethanol cannot cover the cost of production (or both). With that in mind, we investigated the competitiveness of macroalgae-derived sugars, which can be used as a proxy to determine whether a generalized fermentation-based process would be economically favorable compared to the processes based on other sugar sources (e.g., glucose, sucrose, lignocellulosic biomass hydrolyzate, etc.).The MSP values for the two scenarios, i.e., base case and aggregate (corresponding to the scenarios discussed in macroalgae-to-ethanol section) are given in Fig. 6.

The MSP of sugars derived in the base case scenario was in the range of $\phi 33-62 / \mathrm{lb}$ depending on the macroalgae price (\$0-200/MT). With the aggregate scenario, on the other hand, the MSP dropped to $\not 12-31 / \mathrm{lb}$. Depending on the maturity of the advances made with regard to the sugar yield, solids loading, and enzyme loading, the MSP ranged from $\varnothing 21$ to $47 / \mathrm{lb}$ at $\$ 100 /$ MT macroalgae or $\not 16-40 / 1 b$ at $\$ 50 /$ MT of macroalgae - this compares favorably to current market price of sugars at $\sim \not 17 / \mathrm{lb}[35]$. Historically, while there have been significant fluctuations, the sugar price has largely remained downwards of $\phi 20 / \mathrm{lb}$ over the last 10 years, except during 2010-2012 period when it increased to a level of $\not 25-30 / 1 b$ or more. In other words, depending on the market conditions and the advances made with the macroalgae-to-sugar technologies, macroalgae may be an economical renewable feedstock for production of fermentation-derived chemicals. It must be emphasized, however, that the economic viability of the described macroalgae-to-sugar platform does not necessarily translate into a profitable biorefinery, as this would still require viable and scalable downstream technologies (e.g., for product
Fig. 6 Minimum selling price (MSP) of fermentable sugars derived from macroalgae
MSP of Sugar Vs key cost drivers

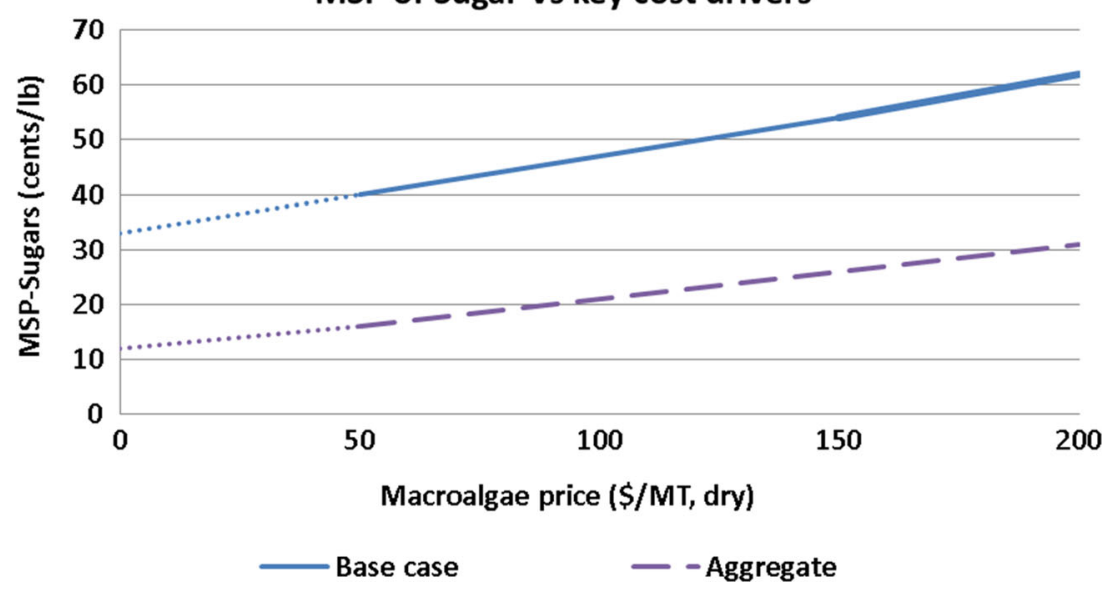


recovery) that result in products with the desired level of purity. The analysis presented here only provides a reference point that can be used to compare with the sugars derived from other feedstocks. Furthermore, not all microbial pathways utilize sugars in the same way, and thus the yield and by-product formation would have to be studied after the product of interest is chosen. In all, these factors point to the need to consider full processes for each chemical to be studied, which is at present limited by the amount of data available in the literature.

Coproduction of Alginate and Its Impact on Process Economics

A key reason behind the challenging economics of macroalgae-based biorefineries is the lack of industrial microbial technologies that could facilitate efficient and economical fermentation of alginate, which is present in significant amounts in brown algae, thereby severely lowering the achievable yields in practice (e.g., [17]). On the other hand, alginate, by itself, is widely used in the textile and food industries as a thickening agent $[21,22]$ and coproducing alginate in a macroalgae-to-ethanol biorefinery could improve overall process economics. For instance, a recent study [36] highlighted the importance and favorable economic impact of alginate extraction within the context of a small-scale biogas facility. Hence, the impact of coproduction of alginate on the process economics was investigated and is discussed in the following section, using the ethanol biorefinery (aggregate scenario) as a basis for analysis.

\section{Cost Comparison of Coproduction of Alginate and Ethanol}

An economic comparison between biorefineries with and without alginate coproduction is given in Fig. 7. It can be seen that coproduction of alginate requires significantly more capital not only because of the additional equipment needed for extraction but also because of the significant amount of water used for filtration in this process, which has a ripple effect on other sections. For example, the additional water used increased the CapEx of the WWT and utility sections. In addition, alginate extraction required a significant amount of chemicals (including $\mathrm{Na}_{2} \mathrm{CO}_{3}, \mathrm{CaCl}_{2}, \mathrm{NaOCl}, \mathrm{HCl}$, and formalin), which increased not only the raw material cost but, subsequently, the waste treatment costs as well. The enzyme cost contribution was less in the alginate coproduction scenario as alginate was extracted prior to hydrolysis, which reduced the amount of enzyme required. However, the added costs of chemicals and natural gas needed to fuel the utility section more than offset the cost savings due to the reduced enzyme requirement and subsequently increased the total cost of raw materials. All these factors explain the significant increase in the AOC of the scenario with alginate coproduction.

Impact of Alginate Coproduction on Macroalgae-to-Ethanol Biorefinery

If the market supply of alginate expands, it is expected that the alginate price would drop, potentially threatening the revenues from coproduction. Therefore, we analyzed the MSP of alginate that would make the biorefinery competitive by fixing the price of ethanol at \$2.5/gal (equivalent to average market price in 2012-2013 [30]). For the alginate coproduction scenario, the MSP of alginate was $\$ 3.1 / \mathrm{kg}$. The total revenues for both the scenarios are shown in Fig. 7. As seen here, due to the alginate, the total revenue in the coproduction scenario was significantly higher and compensates for the additional costs incurred.

By comparison, the current market price of alginate is in the range of $\$ 14-30 / \mathrm{kg}$ (based on a quote from an industrial source) and has historically remained high (i.e., \$9-12/kg during the 1999-2009 period [21]). This implies that the alginate supply can expand and remain competitive if prices remain above $\sim \$ 3.1 / \mathrm{kg}$, which would open other uses for this chemical. Even if the alginate extraction yield drops from 88 to $50 \%$, the MSP of alginate would remain relatively low, at $\sim \$ 5.0 / \mathrm{kg}$. In other words, coproducing alginate in a macroalgae-to-ethanol biorefinery can in principle improve the overall biorefinery economics and the ethanol production can be made economically viable.
Fig. 7 Cost breakdown and revenues of ethanol-only scenario and alginate coproduction scenario

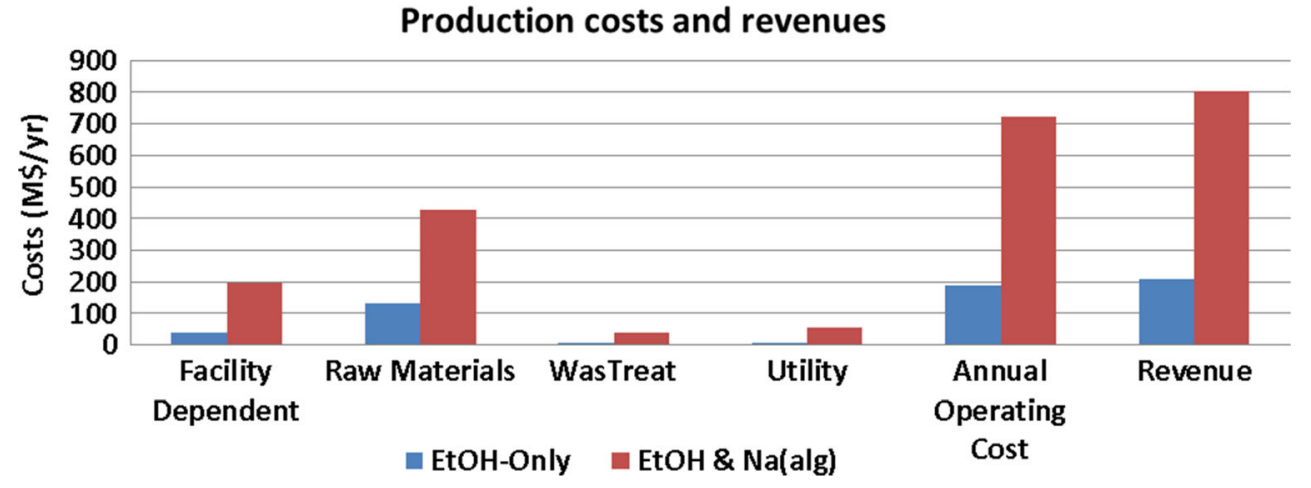


While alginate coproduction seems to improve the profitability of the biorefinery modeled, with the expansion of the technology, market saturation of alginate will become an issue. The amount of alginate that would be produced from a single biorefinery is in the range of $130,000-220,000 \mathrm{MT} /$ year (depending on alginate extraction yield, 50-88\%), while the global demand for alginate is about 26,500 MT/year (2009 estimate[21]). In other words, the alginate production capacity of a single biorefinery far exceeds the global demand (by about five to eight times), resulting in a market with an excess supply of alginate. It could be argued that novel uses of alginate may increase the future demand for this chemical and help absorb some of the excess supply. However, given that the market growth for alginate has been sluggish in the recent past (with an annual increase of 1.5\% during 1999-2009 period [21]), the prospect of a significantly bigger future market is unlikely to trigger the capital investments required for coproduction at all but very small scales.

\section{Conclusions}

In this work, a detailed process model for a macroalgae-based biorefinery was built and an extensive scenario-based TEA was carried out for three main configurations: (1) macroalgae-to-ethanol biorefinery, (2) macroalgae-to-sugars platform, and (3) coproduction of alginate in the context of a macroalgae-to-ethanol biorefinery. Based on the TEA of base case macroalgae-to-ethanol biorefinery, the MESP was $\$ 8.5$ / gal, with costs notably influenced by the macroalgae price, the overall yield, the solids loading in the process and the enzyme loading during hydrolysis. To bring the MESP to a competitive level of $\$ 2.5 / \mathrm{gal}$ or less, multiple advances (i.e., $\geq 80 \%$ yield, $\geq 20 \%$ solids loading, $\leq 10 \mathrm{mg} / \mathrm{g}$ enzyme loading) need to be realized simultaneously and in conjunction with a feedstock price of less than $\sim \$ 26 / \mathrm{MT}$. Given the challenging economics of a macroalgae-to-ethanol biorefinery, the economic feasibility of fermentation-derived chemicals from macroalgae was investigated using a macroalgae-to-sugar platform as a proxy. On this front, depending on the technological parameters and advances in the macroalgae-to-sugar processes (especially in terms of sugar yield, solids loading, and enzyme loading during hydrolysis), fermentable sugars derived from macroalgae may offer an economically viable platform for the production of chemicals under market conditions wherein the price of sugars is high $(>\varnothing 25-30 / \mathrm{lb})$. Though the macroalgae-to-sugars platform is economically favorable, efficient, scalable, and economical downstream technologies (i.e., microbial fermentation and product recovery/purification) are still required for macroalgae-derived chemicals to be cost competitive with chemicals produced from petroleum. While the coproduction of alginate was observed to improve the overall economics of the biorefinery, the expected production of alginate from a single biorefinery (i.e., 130,000-220,000 MT/year) was far greater than its global demand (i.e., 26,500 MT/year). This observation notwithstanding, the analysis highlighted the potential advantage of producing a portfolio of chemicals, as long as market saturation issues are considered. While the observations made in this study are specific to the species studied (S. latissima), our models are flexible and can be easily tuned to investigate the economic potential of the other macroalgae species and other conversion technologies. The model that served as the basis in this study is available for noncommercial use through our wiki (http://econ.jbei.org/).

Acknowledgments This work conducted by the Joint BioEnergy Institute was supported by the Office of Science, Office of Biological and Environmental Research of the US Department of Energy under contract no. DE-AC02-05CH11231. Financial support from Statoil is appreciated. DKM was partly funded by the Dow Centre for Sustainable Engineering Innovation.

Conflict of Interest The authors declare that they have no competing interests.

Authors' Contributions NVSNMK carried out the TEA and drafted the manuscript. DKM conceived the scope and structure of this study and participated in discussions on the results and analysis. DKM, BAS, and SS supervised this work and edited the manuscript. All authors read and approved the manuscript.

Open Access This article is distributed under the terms of the Creative Commons Attribution License which permits any use, distribution, and reproduction in any medium, provided the original author(s) and the source are credited.

\section{References}

1. Schultz-Jensen N, Thygesen A, Leipold F, Thomsen ST, Roslander C, Lilholt H, Bjerre AB (2013) Pretreatment of the macroalgae Chaetomorpha linum for the production of bioethanol - comparison of five pretreatment technologies. Bioresour Technol 140(0):36-42. doi:10.1016/j.biortech.2013.04.060

2. Roesijadi G, Jones S, Snowden-Swan L, Zhu Y (2010) Macroalgae as a biomass feedstock: a preliminary analysis, PNNL 19944. Pacific Northwest National Laboratory, Richland

3. Adams JM, Gallagher JA, Donnison IS (2009) Fermentation study on Saccharina latissima for bioethanol production considering variable pre-treatments. J Appl Phycol 21(5):569-574

4. Jung KA, Lim S-R, Kim Y, Park JM (2013) Potentials of macroalgae as feedstocks for biorefinery. Bioresour Technol 135(0):182-190. doi:10.1016/j.biortech.2012.10.025

5. Somerville C, Youngs H, Taylor C, Davis SC, Long SP (2010) Feedstocks for lignocellulosic biofuels. Science (Washington) 329(5993):790-792

6. Konda NM, Shi J, Singh S, Blanch HW, Simmons BA, KleinMarcuschamer D (2014) Understanding cost drivers and economic potential of two variants of ionic liquid pretreatment for cellulosic biofuel production. Biotechnol Biofuels 7(1):86

7. Klein-Marcuschamer D, Simmons BA, Blanch HW (2011) Technoeconomic analysis of a lignocellulosic ethanol biorefinery with ionic 
liquid pre-treatment. Biofuels Bioprod Biorefin 5(5):562-569. doi: $10.1002 / \mathrm{bbb} .303$

8. Humbird D, Davis R, Tao L, Kinchin C, Hsu D, David. D, Aden A (2011) Process design and economics for biochemical conversion of lignocellulosic biomass to ethanol. Natl Renew Energy Technol 2753000

9. Konda NM, Klein-Marcuschamer D, Simmons BA, Blanch HW Advances in ionic liquid pretreatment technologies: Impact on the economics of cellulosic biofuel production. In: 36th Symposium on Biotechnology for Fuels and Chemicals (April 28-May 1, 2014), 2014. Simb

10. Dave A, Huang Y, Rezvani S, McIlveen-Wright D, Novaes M, Hewitt N (2013) Techno-economic assessment of biofuel development by anaerobic digestion of European marine cold-water seaweeds. Bioresour Technol 135(0):120-127. doi:10.1016/j.biortech. 2013.01.005

11. Adams JMM, Toop TA, Donnison IS, Gallagher JA (2011) Seasonal variation in Laminaria digitata and its impact on biochemical conversion routes to biofuels. Bioresour Technol 102(21):9976-9984. doi: 10.1016/j.biortech.2011.08.032

12. Scullin C, Stavil V, Skarstad A, Peralta-Yahya P, Keasling JD, Simmons BA, Singh S (2014) Optimization of renewable pinene production from the conversion of macroalgae Saccharina latissima. BioResource Technology (Accepted on 20th Sepember 2014) doi: 10.1016/jbiortech201409105

13. Madonna J. Macroalgae and Biofuel OPIM 5894 Principles of global sustainability

14. Burton T, Lyons H, Lerat Y, Stanley M, Rasmussen MB (2009) A review of the potential of marine algae as a source of biofuel in Ireland. Sustainable Energy Ireland-SEI, Dublin

15. LBNL (2013) JBEI Technoeconomic Model: The Sequels (http:// newscenter.lbl.gov/2013/09/09/technoeconomic-model-the-sequels/)

16. Kerner KN, Hanssen JF, Pedersen TA (1991) Anaerobic digestion of waste sludges from the alginate extraction process. Bioresour Technol 37(1):17-24. doi:10.1016/0960-8524(91)90107-U

17. Wargacki AJ, Leonard E, Win MN, Regitsky DD, Santos CNS, Kim PB, Cooper SR, Raisner RM, Herman A, Sivitz AB (2012) An engineered microbial platform for direct biofuel production from brown macroalgae. Science 335(6066):308-313

18. Kim N-J, Li H, Jung K, Chang HN, Lee PC (2011) Ethanol production from marine algal hydrolysates using Escherichia coli KO11. Bioresour Technol 102(16):7466-7469. doi:10.1016/j.biortech. 2011.04.071

19. Klein-Marcuschamer D, Oleskowicz-Popiel P, Simmons BA, Blanch HW (2012) The challenge of enzyme cost in the production of lignocellulosic biofuels. Biotechnol Bioeng 109(4):1083-1087

20. Hernández-carmona G, McHugh D, Arvizu-Higuera D, Rodríguezmontesinos YE (1998) Pilot plant scale extraction of alginate from Macrocystis pyrifera. 1. Effect of pre-extraction treatments on yield and quality of alginate. J Appl Phycol 10(6):507-513. doi:10.1023/ A: 1008004311876

21. Bixler H, Porse H (2011) A decade of change in the seaweed hydrocolloids industry. J Appl Phycol 23(3):321-335. doi:10.1007/ s10811-010-9529-3
22. FAO Alginate (http://www.fao.org/docrep/006/y4765e/y4765e 08. htm)

23. Hernández-Carmona G, McHugh D, López-Gutiérrez F (1999) Pilot plant scale extraction of alginates from Macrocystis pyrifera. 2 . Studies on extraction conditions andmethods of separating the alkaline-insoluble residue. J Appl Phycol 11(6):493-502. doi:10. 1023/A:1008114709681

24. Hernández-Carmona G, McHugh D, Arvizu-Higuera D, RodríguezMontesinos YE (2002) Pilot plant scale extraction of alginates from Macrocystis pyrifera 4. Conversion of alginic acid to sodium alginate, drying and milling. J Appl Phycol 14(6):445-451. doi:10.1023/ A:1022372807813

25. McHugh D, Hernández-Carmona G, Luz Arvizu-Higuera D, Rodríguez-Montesinos YE (2001) Pilot plant scale extraction of alginates from Macrocystis pyrifera 3. Precipitation, bleaching and conversion of calcium alginate to alginic acid. J Appl Phycol 13(6): 471-479. doi:10.1023/A:1012532706235

26. Ge L, Wang P, Mou H (2011) Study on saccharification techniques of seaweed wastes for the transformation of ethanol. Renew Energy 36(1):84-89. doi:10.1016/j.renene.2010.06.001

27. Klein-Marcuschamer D, Oleskowicz-Popiel P, Simmons BA, Blanch HW (2010) Technoeconomic analysis of biofuels: A wiki-based platform for lignocellulosic biorefineries. Biomass Bioenergy 34(12): 1914-1921. doi:10.1016/j.biombioe.2010.07.033

28. Klein-Marcuschamer D, Turner C, Allen M, Gray P, Dietzgen RG, Gresshoff PM, Hankamer B, Heimann K, Speight R, Nielsen LK (2013) Technoeconomic analysis of renewable aviation fuel from microalgae, Pongamia pinnata, and sugarcane. Biofuels Bioprod Bioref

29. Aden A, Ruth M, Ibsen K, Jechura J, Neeves K, Sheehan J, Wallace B, Montague L, Slayton A, Lukas J (2002) Lignocellulosic biomass to ethanol process design and economics utilizing co-current dilute acid prehydrolysis and enzymatic hydrolysis for corn stover. DTIC Document

30. EIA AEO2014 Early Release Overview

31. Alvarado-Morales M, Boldrin A, Karakashev DB, Holdt SL, Angelidaki I, Astrup T (2013) Life cycle assessment of biofuel production from brown seaweed in Nordic conditions. Bioresour Technol 129(0):92-99. doi:10.1016/j.biortech.2012.11.029

32. Kristensen JB, Felby C, Jørgensen H (2009) Yield-determining factors in high-solids enzymatic hydrolysis of lignocellulose. Biotechnol Biofuels 2(1):11

33. Mussatto S, Dragone G, Fernandes M, Milagres AF, Roberto I (2008) The effect of agitation speed, enzyme loading and substrate concentration on enzymatic hydrolysis of cellulose from brewer's spent grain. Cellulose 15(5):711-721. doi:10.1007/s10570-008-9215-7

34. Casey E, Mosier NS, Adamec J, Stockdale Z, Ho N, Sedlak M (2013) Effect of salts on the Co-fermentation of glucose and xylose by a genetically engineered strain of Saccharomyces cerevisiae. Biotechnol Biofuels 6(1):83

35. NASDAQ (July 2014) Latest price and chart for sugar

36. Langlois J, Sassi J-F, Jard G, Steyer J-P, Delgenes J-P, Hélias A (2012) Life cycle assessment of biomethane from offshorecultivated seaweed. Biofuels Bioprod Biorefin 6(4):387-404. doi: $10.1002 / b b b .1330$ 